\title{
"The post-COVID era": challenges in the treatment of substance use disorder (SUD) after the pandemic
}

\author{
Hugo López-Pelayo ${ }^{1,2^{*}}$ (D), Henri-Jean Aubin ${ }^{3,4,5}$, Colin Drummond ${ }^{6,7}$, Geert Dom ${ }^{8,9,10,11}$, Francisco Pascual ${ }^{12,13,14,15}$,
} Jürgen Rehm ${ }^{16,17,18,19}$, Richard Saitz ${ }^{20,21,22}$, Emanuele Scafato ${ }^{23,24}$ and Antoni Gual ${ }^{25,26}$

\begin{abstract}
Background: Citizens affected by substance use disorders are high-risk populations for both SARS-CoV-2 infection and COVID-19-related mortality. Relevant vulnerabilities to COVID-19 in people who suffer substance use disorders are described in previous communications. The COVID-19 pandemic offers a unique opportunity to reshape and update addiction treatment networks.

Main body: Renewed treatment systems should be based on these seven pillars: (1) telemedicine and digital solutions, (2) hospitalization at home, (3) consultation-liaison psychiatric and addiction services, (4) harm-reduction facilities, (5) person-centered care, (6) promote paid work to improve quality of life in people with substance use disorders, and (7) integrated addiction care. The three "best buys" of the World Health Organization (reduce availability, increase prices, and a ban on advertising) are still valid. Additionally, new strategies must be implemented to systematically deal with (a) fake news concerning legal and illegal drugs and (b) controversial scientific information.

Conclusion: The heroin pandemic four decades ago was the last time that addiction treatment systems were updated in many western countries. A revised and modernized addiction treatment network must include improved access to care, facilitated where appropriate by technology; more integrated care with addiction specialists supporting non-specialists; and reducing the stigma experienced by people with SUDs.
\end{abstract}

Keywords: Addictions, COVID-19, Substance use disorder, Stigma, Telemedicine, Harm-reduction

\section{Background}

"Things do not change; we change" (Henry D. Thoreau). As Thoreau stated two centuries ago, the material world will not change, but after the pandemic, will humanity change? And what are the challenges we are facing in the treatment of substance use disorders (SUDs)? This

\footnotetext{
* Correspondence: hlopez@clinic.cat

'Grup Recerca Addiccions Clínic (GRAC-GRE), Institut d'Investigacions Biomèdiques August Pi I Sunyer (IDIBAPS), Hospital Clínic Barcelona, Rosselló 149, 08036 Barcelona, Spain

${ }^{2}$ Socidrogalcohol (Spanish Society of Drug and Alcohol Specialists), Barcelona, Spain

Full list of author information is available at the end of the article
}

short communication describes those challenges, and how to deal with them once the current pandemic declines, in the likely context of scarce resources.

\section{Current situation of COVID-19 and SUDs}

The outbreak of severe acute respiratory syndrome coronavirus 2 (SARS-CoV-2) was considered a pandemic on March 11, 2020, by the World Health Organization. Many countries responded with physical distancing measures, reorganization of healthcare systems, lockdown regulations, and contingency plans for the economic situation [1].

(c) The Author(s). 2020 Open Access This article is licensed under a Creative Commons Attribution 4.0 International License, which permits use, sharing, adaptation, distribution and reproduction in any medium or format, as long as you give appropriate credit to the original author(s) and the source, provide a link to the Creative Commons licence, and indicate if changes were made. The images or other third party material in this article are included in the article's Creative Commons licence, unless indicated otherwise in a credit line to the material. If material is not included in the article's Creative Commons licence and your intended use is not permitted by statutory regulation or exceeds the permitted use, you will need to obtain permission directly from the copyright holder. To view a copy of this licence, visit http://creativecommons.org/licenses/by/4.0/. The Creative Commons Public Domain Dedication waiver (http://creativecommons.org/publicdomain/zero/1.0/) applies to the data made available in this article, unless otherwise stated in a credit line to the data. 
Citizens affected by SUDs are high-risk populations for both SARS-CoV-2 infection and COVID-19-related mortality. Relevant vulnerabilities to COVID-19 in people who suffer SUD are described elsewhere (summary in Table 1).

Telemedicine for mental health problems including SUDs has taken a more central role during the crisis, showing its feasibility and minimizing the risk of virus transmission while providing continuity of care [10]. Telemedicine offers the promise of increased adherence to treatment, since a number of logistical barriers associated with physical attendance at treatment services are removed. In some countries (e.g., USA, Canada), confidentiality regulations and regulations requiring frequent inperson contact for those being treated with medication have been lifted during the public health emergency, thus making care more accessible and patient-centered than before. However, during this crisis, digital solutions have been hastily improvised and often lack support in the form of clinical guidelines for people with SUDs [11]. The addiction field has experienced a rapid increase of effective web-based teleconsultation platforms, which have created new methods of engaging with people with SUDs that are likely to continue after the crisis [12, 13]. Some specific groups (e.g., those with physical or cognitive comorbidities or health inequalities) may not be reached by these digital solutions, increasing the risk of social exclusion through the digital divide.

For the most severe cases, hospitalization at home has been a feasible solution [10]. Another solution has been designated COVID-19 wards or areas of outpatient treatment programs. Harm-reduction services have continued working in many countries (e.g., Canada, Spain, UK), but unfortunately, in other regions, they have had to reduce or pause their activities. The decrease in drug availability and consequences of this (e.g., withdrawal syndrome, reductions in purity) $[9,14]$ have led to rapid changes in clinical routines (e.g., larger take-home doses of methadone, reduced frequency of supervised consumption) [15]. Patients who have suffered from both SUDs and COVID-19 have been admitted to hospitals, requiring support from consultation-liaison psychiatry/ addiction units due to pharmacological interactions, severe withdrawal syndromes including delirium tremens, craving management, or behavioral disturbances. Quarantine for homeless people who suffer SUDs has been organized through emergency shelters, which have unwittingly become an example of a "housing first" policy.

In summary, a range of new care approaches have been offered to people with SUDs during the COVID-19 pandemic, but many of these have been implemented hastily and need to be evaluated as we adapt to the next phases of the pandemic. New plans for care of people who suffer from SUDs in the "post-COVID-19 era" need to be developed, as we know this is a highly vulnerable group from economic, social, and health perspectives.

\section{The day after the pandemic and SUD treatment services}

A global economic recession is expected [16], and its impact on drug use is currently unknown. We may expect decreased levels of substance use in the short term, due to decreased availability and affordability $[17,18]$. However, the medium-term scenario is likely to be an increase in consumption for some populations as a consequence of increased emotional distress and psychiatric comorbidity $[19,20]$.

The COVID-19 pandemic and associated economic recession are causing isolation, unemployment, boredom, and emotional distress, factors that we know impact negatively and increase alcohol and other drug use [21-23]. Conversely, financial restrictions, reduced availability of illicit drugs, and higher prices of these during the lockdown have been well documented [24]. These factors have been shown to reduce alcohol and drug use, despite the fact that bars and cannabis social clubs reopened before schools and universities in some countries $[25,26]$. In short, the existing literature identifies three factors which would tend to decrease substance use in this situation (reduced availability, higher prices, and financial restrictions) and three factors related to economic crises which could

Table 1 Summary of risk factors for COVID-19 in people affected by SUD

\begin{tabular}{|c|c|}
\hline Substance-related factors [2-7] & Contextual and pattern of use related factors $[8,9]$ \\
\hline $\begin{array}{l}\text { - A protective effect of nicotine has been claimed, but a systematic review } \\
\text { ( } 5 \text { studies, } n=1358 \text { ) has shown that smoking is associated with adverse } \\
\text { outcomes of COVID-19. Another study ( } 169 \text { hospitals, } n=8910 \text { ) found } \\
\text { the risk of death for current smokers during hospitalization due to } \\
\text { COVID-19 } 79 \% \text { higher than in non-smokers. } \\
\text { - Alcohol use, especially heavy use, weakens the innate and acquired } \\
\text { immune systems, thus increasing the risk of infections such as tuberculosis, } \\
\text { HBV, HCV, HIV-AIDS, or COVID-19, and worsening the course of the disease. } \\
\text { Heavy drinking is a well-established risk factor for acute respiratory distress } \\
\text { syndrome. } \\
\text { - Regular cannabis use is associated with coughing and other respiratory } \\
\text { symptoms. }\end{array}$ & $\begin{array}{l}\text { - Lung injuries related to vaping and/or smoking. } \\
\text { - Lack of access to hand washing, disinfecting wipes, and personal } \\
\text { protective equipment (PPE), and overcrowding among certain groups } \\
\text { of people who use drugs (e.g., those in incarceration, homelessness). } \\
\text { - Pulmonary hypertension associated with methamphetamine use. } \\
\text { - Compromised immune function. } \\
\text { - Stigma of drug and alcohol use as a barrier to accessing healthcare. } \\
\text { - Sharing cigarettes, drinks, or needles is high-risk behaviors for becoming } \\
\text { infected with SARS-CoV-2. } \\
\text { - Lockdown has had an impact on illicit drug supplies, with a subsequent } \\
\text { impact on behaviors of people who use substances. }\end{array}$ \\
\hline
\end{tabular}


lead to increases in substance use (emotional distress, isolation, and unemployment).

Experiences from previous pandemics (e.g., SARS 2003) and natural or man-made disasters suggest a medium- and long-term increase in alcohol and drug use and consequent negative impacts after the pandemic [19].

Furthermore, the legal "drug" market (alcohol or tobacco) and "semi-legal drug" market (cannabis) will strive to maintain and even increase sales opportunities [27]. During the crisis, at least in high-income countries, some parts of the mainstream media and social media have encouraged people to drink when bored or to relieve stress [28]. In the US states where cannabis is legally available, medical cannabis shops have been deemed essential businesses, and there has been a surge in certification to receive medical cannabis. It is likely that this represents an increase in use which will in due course translate into incident cannabis use disorders and related harms.

As in the 2008 economic crisis, social and economic troubles will disproportionately affect those in the most vulnerable situations, including people with SUDs [20]. This population will request help not just for SUD but also for the consequences in other domains of health: especially in mental health, housing, and access to medications or other fundamental goods [17, 29]. Healthcare and social care systems need to prepare to cope with a likely increase in demand in this population.

A second concern is the competition for economic resources between SUDs and other disorders, and "new stigmatization." Stigma is already an obstacle for treating people affected by SUDs [30]. In times of scarce resources, social stigma may influence how the allocation of economic resources is prioritized, leading to increased and systemic discrimination. Frontline healthcare staff and other at-risk populations will need mental health support after the pandemic [31]. Elective surgery and other interventions that have been put on hold during the pandemic will require increased resources to clear the backlog. In this scenario, governing politicians may be tempted to relegate SUD treatment to the end of the queue, even though this would be a "false economy," as the problems are likely to be displaced onto already overstretched emergency services and acute hospitals [32].

\section{Main text}

\section{How to prevent new stigmatization and even take} advantage of the new opportunities: seven pillars

New clinical approaches implemented during the pandemic have helped to mitigate its impact on SUD treatment. But will they remain after the COVID-19 pandemic? We strongly advocate taking advantage of innovations initiated during the pandemic and continuing to develop them in a post-COVID-19 world. This situation is an opportunity to modernize SUD treatment, which is still largely based on that developed a century ago and only updated 40 years ago during the heroin pandemic. We believe that the renewed treatment systems should be based on the seven pillars described below. An overarching priority is to assure the renewal relies heavily if not exclusively on delivering treatments that have been proven to be effective, avoiding the temptation to use services that might seem to be readily available or that are promoted but that have no value.

Acceleration in the implementation of pillars 1 (telemedicine) and 2 (home hospitalizations) is necessary to cope with short-term and direct consequences of the pandemic, while pillars 3 to 7 are long-term and general measures to improve SUD treatment for the future.

\section{Pillar 1: Telemedicine and digital solutions}

Telemedicine in addiction shows favorable results for reduction of alcohol use and depressive symptoms; increased quality of life, patient satisfaction, and accessibility; and can be delivered at reduced cost [33]. Evidence for the efficacy of digital interventions is of good quality for alcohol and cannabis use disorders [34, 35]. During the COVID-19 pandemic, our anecdotal experience is that patients find such treatment more accessible and easier to adhere to. Some potential risks need systematic evaluation, such as larger prescriptions of opioid agonists, and less biological testing (e.g., urine drug testing) and clinical supervision. Additional technological solutions may also help to minimize these risks. In some countries, such as the USA, a proportion of the organizations were already in a better position to cope with the pandemic using telemedicine. A 2018 study found that $45 \%$ of 363 SUD organizations in the USA offered computerized screening and/or assessments, almost 30\% provided telephone support or treatment, and 20\% already offered video therapy [36]. Successful experiences with telemedicine in Italy, Spain, France, and the USA were reported during the current crisis, although these observations have not been backed up with specific clinical data [10,37, 38].

However, use of technology in the SUD field is not just limited to online appointments. Smartphone and web-based interventions, text messaging for continuing contact and care, machine learning, and wearable devices, including digital phenotyping and ecological momentary assessment, biofeedback, and virtual reality, expand the range of available treatment opportunities and provide tools to help professionals and patients to make shared decisions $[39,40]$.

There is a need for a public health response to increase availability of treatment for SUDs, including training for healthcare professionals in online interventions and counseling. The concept of tele-expertise has also emerged as a new strategy that could be valuable in 
mitigating the impact of the pandemic on the SUD treatment system. In the tele-expertise framework, an addiction specialist could distantly supervise the work of other health professionals in the field [41].

\section{Pillar 2: Home hospitalizations}

Intensive outpatient treatments range in format from daily outpatient care in a hospital or center (e.g., day hospital) to home hospitalization. There are successful experiences in mental illness worldwide and emerging programs in SUD treatment [42-45].

Active healthcare treatment in the patient's home (home hospitalization) is an alternative to inpatient treatment that has shown a reduction in readmissions, improvement of patient's satisfaction, and reduction of hospital length of stay, with little or no differences in mortality for many medical conditions [46]. The evidence in the treatment of mental health disorders is more limited. Hospitalization at home has been implemented as an alternative for inpatient mental health treatment with encouraging results in both adults and children and adolescents [47, 48], and has shown feasibility during the COVID-19 crisis [10]. We strongly recommend that research and clinical practice of mental health home hospitalization include patients affected by SUDs. Furthermore, the link between telemedicine and home hospitalization may include nursing as daily contact and psychiatric and psychological support provided remotely.

In addition to home hospitalization, staying at home can also be viewed as "outpatient" treatment (e.g., where the patient is at home and has contact with a clinician electronically) and may for many people be preferable to inpatient treatment. Few if any studies find benefit for inpatient versus outpatient treatment for SUD, and thus, it is more appropriately reserved for patients who have no sober place to stay, lack social support or are vulnerable, need medical or psychiatric hospitalization, or have very severe SUD. During the pandemic, access to inpatient SUD care has been limited and greater use of outpatient treatment postCOVID-19 represents an advance in quality of care that should be maintained.

Since people living in deprived conditions are especially vulnerable to SUDs $[49,50]$, the implementation of pillars 1 and 2 should be carried out while in maintaining a focus on methods and processes which do not increase existing inequalities in treatment access.

\section{Pillar 3: Consultation-liaison psychiatric and addiction services}

Admission due to health problems in an acute hospital is an excellent opportunity to detect and manage SUDs, especially for patients with alcohol, opioid, and cocaine use disorders and multiple somatic and mental comorbidities [51]. Additionally, admission creates an opportunity for people with SUDs to access treatment at an earlier stage and close the treatment gap.

Multidisciplinary treatment facilitates the treatment of underlying conditions in many areas such as emergency departments, liver units, or head and neck surgery units [52]. It is also a helpful strategy to reduce stigmatization of people with SUDs and to promote an integrated treatment approach, with clinicians from different backgrounds (e.g., nursing, social workers, hepatologists, addiction specialists) working in an integrated way.

\section{Pillar 4: Harm-reduction facilities}

Abstinence is the most desirable objective for SUDs from a health perspective, but in some circumstances, this is not realistic (e.g., in severe and complex cases). Harmreduction is a perfectly reasonable intermediate goal that many people can successfully achieve [53]. Harmreduction aims and has been shown to reduce mortality and morbidity through a reduction in risk behaviors or a reduction of drug use, and is implemented in many countries because of its effectiveness [54]. "Housing first" is a practice for homeless people with co-occurring serious mental illness and SUD, which focuses on providing a stable home without requiring prior abstinence. This approach reduces homelessness and health service utilization and is efficient [55]. And, helpfully, albeit unwittingly, it has been used during the COVID-19 crisis to ensure the quarantine of this population.

\section{Pillar 5: Person-centered care}

Person-centered care is clearly preferred by patients, and advocated by many clinicians, but has not been widely implemented due to a combination of arcane regulatory structures and clinical inertia. During the acute phase of the pandemic, this has been put in place on an emergency basis. Patient preferences for fewer in-person visits and testing, easier access to enter into and receive treatment, and fewer prescribing restrictions are likely to have improved the quality of care and access to it. These should be retained post-COVID-19 as key elements of any new treatment system. Motivational interviewing (MI) and shared decision-making (SDM) are two effective approaches to SUD that have shown increasing evidence in the last 30 years $[56,57]$. They have in common: (1) an ethical approach to SUD management, focusing on the self-determination principle (autonomy); (2) flexibility in objectives and treatment decisions; and (3) both remove the stigma of SUD. In other words, MI and SDM facilitate person-centered care. 


\section{Pillar 6: Promote paid work to improve quality of life in people with SUDs}

Having meaningful paid work contributes significantly to both better outcomes and a reduction in healthcare costs for SUD patients, specifically (but not exclusively) for those with complex mental health comorbidities [58, 59]. In the aftermath of the COVID-19 pandemic, there have been many calls for future economic structures which lead to more sustainable economies, with a broader, socially inclusive scope [60]. We need to work together with these societal actors to include SUD patients in these new work contexts. The implementation of strategies such as "paid work or housing first" can be challenging in times of recession, when the forecast (from the International Labour Office) indicates that $6.7 \%$ of working hours will likely be lost during the second trimester of 2020 [61].

\section{Pillar 7: Integrated addiction care}

Reducing pressure and costs on acute and mental healthcare will be a priority after the pandemic due to increased demands on health systems. Cutting addiction services is a false economy as the impact is displaced onto already overstretched hospitals [32]. The solution is an integrated addiction care model that spans from early detection and brief interventions in primary care (both health and social) to highly specialized hospital services. Within this integrated approach, gambling and gaming problems deserve special attention.

The way to end the stigma experienced by these groups is to fully respect the civil rights of people with SUDs, including equality of access to health services. From the addiction treatment perspective, we have to guarantee access to evidence-based treatments in a modernized healthcare system, with these seven pillars offering a guide on how to do this and concurrently reduce stigma.

\section{Public health and prevention}

Even though this communication focuses on SUDs and their treatment, in a time of crisis, it is also very important to implement preventive activities and take a public health perspective. Public health responses must be based on a realistic analysis of needs. The three "best buys" of the WHO (reduce availability, increase prices, and a ban on advertising) [62] and other evidence-based public health preventive strategies should be reinforced for legal drugs, including the alcohol, tobacco, and gambling markets (online and offline). In addition, new strategies must be implemented to systematically deal with (a) fake news concerning legal and illegal drugs and (b) controversial scientific information and messages (e.g., nicotine and protection from COVID-19)-especially when society is in a state of collective panic, people look for "the truth," and science needs more time and greater integrity to provide clear answers.

The short-term impact of the pandemic has already been described, and relevant institutions (EMCDDA, AMSA, SAMSHA, and NIDA) have published guidelines on the management of this situation [8, 63-65]. This article focuses on the opportunities that could exist in the wake of the pandemic to make long-overdue improvements to the long-term healthcare of people who suffer from SUDs. We are fully aware that our world is facing a period of uncertainty and that this comes in a time that healthcare workers and systems are chronically overstretched. Nevertheless, we strongly feel the priorities outlined in the seven pillars should serve as a guide in the redesign of drug policies worldwide, irrespective of the different impacts and experiences of the COVID-19 outbreaks. Specifically, we think that the implementation of pillars 1 (telemedicine) and 2 (home hospitalizations) should be done quickly, as a short-term response to the pandemic, while pillars 3 to 7 represent much needed long-term and general measures to improve SUD treatment.

\section{Conclusions}

The heroin pandemic four decades ago represents the most recent opportunity to update addiction treatment systems in many western countries. Now, the COVID-19 pandemic offers a unique opportunity to reshape and update addiction treatment networks, to properly face the challenges of the twenty-first century. This should include improved access to care, facilitated where appropriate by technology; more integrated care with addiction specialists supporting non-specialists; and reducing the stigma experienced by people with SUDs.

"Things MIGHT NOT change, but we MUST change", at least to prevent the patients who suffer SUDs being last in the queue yet again.

\section{Abbreviations}

COVID-19: Coronavirus disease 2019; SARS-CoV-2: Severe acute respiratory syndrome coronavirus 2; SUDs: Substance use disorders

\section{Acknowledgements}

We thank Fleur Braddick, Sara Mansilla, and Astrid Otto for writing assistance.

\section{Authors' contributions}

$A G, J R$, and HL-P designed the study. HLP and AG wrote the first draft of the manuscript. All the other authors reviewed and approved the final paper.

\section{Authors' information}

Authors are experts in addiction research and with high levels of responsibility in national and international scientific societies. Authors are seriously concerned for the COVID-19 pandemic and its impact on people affected by SUDs. Their countries have directly been struck by the crisis. They thought that learning from the pandemic may help to reshape the addiction treatment network. The content of this paper is based on professional experience (personal and colleagues), scientific literature, and general media. HLP is the acting vice president of the Spanish society of drugs and drug disorders (Socidrogalcohol) and a member of Research Group on Addictions 
of IDIBAPS; FP is the current president of Socidrogalcohol and a member of Prevengo Research Group of UMH; JHA is a Professeur in the Université Paris-Saclay, the honorary president of Société Française d'Alcoologie, and a member of the Centre de Recherche epidémiologie et Santé des Populations; GD is the president of Belgian Professional Psychiatry Association, the president of European Federation of Addiction Societies (EUFAS), and the chair of Section Addictive Behaviors of European Psychiatric Association (EPA); CD is a professor of Addiction Psychiatry in the King's College London, and the senior vice president of EUFAS; ES is the Director of WHO Collaborating Centre on Research and Health-Osservatorio Nazionale Alcol, and the past president of Società Italiana di Alcologia; RS is the chair and a professor of Department of Community Health Sciences (CHS) in the Boston University. JR is a professor in Dalla Lana School of Public Health and Department of Psychiatry in University of Toronto and a member of the WHO Expert Committee on Substance Abuse; TG is the vice president of INEBRIA, the past president of EUFAS, and the head of Research Group on Addictions of IDIBAPS.

Views expressed in this article are those of the authors only and do not necessarily reflect the views of the societies or institutions.

\section{Funding}

CD is part funded by the UK Department of Health and Social Care (DHSC) National Institute of Health Research (NIHR) Biomedical Research Centre at South London and Maudsley NHS Foundation Trust, the NIHR Applied Research Collaboration South London, and is in receipt of an NIHR Senior Investigator Award. The views expressed here do not necessarily represent those of the DHSC or NIHR.

HLP works under CERCA Programme/Generalitat de Catalunya and receives funding from the Spanish Ministry of Science, Innovation and Universities, Instituto de Salud Carlos III through a "Juan Rodes" contract (JR19/00025).

\section{Availability of data and materials}

Not applicable

\section{Ethics approval and consent to participate}

Not applicable

\section{Consent for publication}

Not applicable

\section{Competing interests}

Dr. Pascual received research grants (Camurus) and lectures/training programs (Lundbeck, Gilead, Abbvie, Neuraxpharm, Pfizer).

Dr. Aubin reported being a member of advisory boards or DSMB for Bioprojet, CV Sciences, and Ethypharm, and has received sponsorship to attend scientific meetings, speaker honoraria, or consultancy fees from Bioprojet, D\&A Pharma, Ethypharm, Kinnov Pharmaceuticals, and Lundbeck. $\mathrm{He}$ is also a member of the American Society of Clinical

Psychopharmacology's Alcohol Clinical Trials Initiative (ACTIVE), which was supported in the last 3 years by Alkermes, Amygdala Neurosciences, Arbor Pharmaceuticals, Ethypharm, Indivior, Lundbeck, Mitsubishi, and Otsuka. Dr. Gual received a grant from Novartis for a trial on cocaine that ended in April 2020.

Dr. López-Pelayo received training grants (Exeltis, Lundbeck).

Dr. Saitz declares that Alkermes provides medication to Boston University for a trial supported by the US National Institutes of Health for which Dr. Saitz is the principal investigator. Dr. Saitz consults for various non-profit institutions and universities as a lecturer, expert, researcher, and editor in the area of addiction. He is the Editor-in-Chief of Journal of Addiction Medicine and the President of International Society of Addiction Journal Editors. He is an investigator for studies supported by the National Institutes of Health and faculty for a training program supported by the Burroughs Wellcome Foundation.

Dr. Dom is a member of the scientific advisory board of Janssen-Cilag NV, Belgium.

None of the previous conflicts of interest has relationship with this work. Others authors do not report any conflict of interest.

\section{Author details}

'Grup Recerca Addiccions Clínic (GRAC-GRE), Institut d'Investigacions Biomèdiques August Pi I Sunyer (IDIBAPS), Hospital Clínic Barcelona, Rosselló
149, 08036 Barcelona, Spain. ${ }^{2}$ Socidrogalcohol (Spanish Society of Drug and Alcohol Specialists), Barcelona, Spain. ${ }^{3}$ Département de psychiatrie et d'addictologie, Université Paris-Saclay, Route de l'Orme aux Merisiers - RD 12891190 Saint-Aubin, Paris, France. ${ }^{4}$ Centre de Recherche en Epidémiologie et Santé des Populations (CESP), INSERM 1018, Paris, France. ${ }^{5}$ Groupe Hospitalo-Universitaire AP-HP, Paris, France. ${ }^{6}$ Addiction Psychiatry, Addictions Department, National Addiction Centre, Institute of Psychiatry, Psychology and Neuroscience King's College, 16 De Crespigny Park, Camberwell, London SE5 8AF, UK. ' European Federation of Addiction Societies (EUFAS), 16 De Crespigny Park, Camberwell, London SE5 8AF, UK. ${ }^{8}$ Antwerp University (UA, (APRI), Antwerp, Belgium. ${ }^{9}$ Belgian Professional Psychiatry Association, Antwerp, Belgium. ${ }^{10}$ European Federation of Addiction Societies (EUFAS), Antwerp, Belgium. ${ }^{11}$ European Psychiatric Association (EPA), Prinsstraat 13, 2000 Antwerp, Belgium. ${ }^{12}$ SOCIDROGALCOHOL, Barcelona, Spain. ${ }^{13}$ CAARFE, Valencia, Spain. ${ }^{14}$ Departamento de Biología Aplicada, Alicante, Spain. ${ }^{15}$ UCA, Alcoy, Alicante, Spain. ${ }^{16}$ Institute for Mental Health Policy Research \& Campbell Family Mental Health Research Institute, Centre for Addiction and Mental Health (CAMH), Toronto, Canada. ${ }^{17}$ Dalla Lana School of Public Health and Department of Psychiatry, University of Toronto (UofT), 155 College St., Toronto, Canada. ${ }^{18}$ Epidemiological Research Unit, Technische Universität Dresden, Klinische Psychologie and Psychotherapie, Dresden, Germany. ${ }^{19}$ Department of International Health Projects, Institute for Leadership and Health Management, I.M. Sechenov First Moscow State Medical University, Moscow, Russian Federation. ${ }^{20}$ Department of Community Health Sciences (CHS), Boston University School of Public Health, 715 Albany St, Boston, MA 02118, USA. ${ }^{21}$ Medicine, Clinical Addiction Research and Education (CARE) Unit, Section of General Internal Medicine, Boston University School of Medicine, Boston, MA 02118, USA. ${ }^{22}$ Grayken Center on Addiction, Boston Medical Center, Boston, MA 02118, USA. ${ }^{23}$ WHO Collaborating Centre on Research and Health-Osservatorio Nazionale Alcol, Promotion on Alcohol and Alcohol-related Health, Problems (ITA-79), Istituto Superiore di Sanità, Rome, Italy. ${ }^{24}$ Società Italiana di Alcologia - SIA, EUFAS Istituto Superiore di Sanità, Rome, Italy. ${ }^{25}$ Grup Recerca Addiccions Clínic (GRAC-GRE), Institut d'Investigacions Biomèdiques August Pi I Sunyer (IDIBAPS), Hospital Clínic Barcelona, Rosselló 149, 08036 Barcelona, Spain. ${ }^{26}$ International Network on Brief Interventions for Alcohol and Other Drugs (INEBRIA), Barcelona, Spain.

Received: 15 May 2020 Accepted: 1 July 2020

Published online: 31 July 2020

\section{References}

1. World Health Organisation. WHO Response in Countries. https://www.who. int/emergencies/diseases/novel-coronavirus-2019/donate/who-response-incountries. Accessed 4 May 2020.

2. Miyara M, Tubach F, POURCHER V, Morelot-Panzini C, Pernet J, Haroche J, et al. Low incidence of daily active tobacco smoking in patients with symptomatic COVID-19. Qeios. 2020. doi:https://doi.org/10.32388/WPP19W.3.

3. Vardavas C, Nikitara K. COVID-19 and smoking: a systematic review of the evidence. Tob Induc Dis. 2020;18 March. doi:https://doi.org/10. 18332/tid/119324.

4. Mehra MR, Desai SS, Kuy S, Henry TD, Patel AN. Cardiovascular disease, drug therapy, and mortality in covid-19. N Engl J Med. 2020;:NEJMoa2007621. doi: https://doi.org/10.1056/NEJMoa2007621.

5. Rehm J, Gmel GE, Gmel G, Hasan OSM, Imtiaz S, Popova S, et al. The relationship between different dimensions of alcohol use and the burden of disease_an update. Addiction. 2017;112:968-1001.

6. Simou E, Leonardi-Bee J, Britton J. The effect of alcohol consumption on the risk of ARDS: a systematic review and meta-analysis. Chest. 2018;154:58-68.

7. Campeny E, López-Pelayo H, Nutt D, Blithikioti C, Oliveras C, Nuño L, et al. The blind men and the elephant: systematic review of systematic reviews of cannabis use related health harms. Eur Neuropsychopharmacol. 2020;33:1-35.

8. Volkow ND. Collision of the COVID-19 and addiction epidemics. Ann Intern Med. 2020. https://doi.org/10.7326/M20-1212.

9. UNODC. COVID-19 and the drug supply chain: from production and trafficking to use. 2020. www.unodc.org. Accessed 8 May 2020.

10. Vieta E, Pérez V, Arango C. LA PSIQUIATRÍA EN LAS SECUELAS DE COVID-19. Rev Psiquiatr Salud Ment. 2020. https://doi.org/10.1016/j.rpsm.2020.04.004.

11. Schmidt-Weitmann S, Bösch S, Weidt S, Brockes C. Psychological online consultation service attracts men: a new approach to close the gap 
between being ill and being treated. Telemed J E Health. 2015;21:48-54. https://doi.org/10.1089/tmi.2013.0370.

12. American Society of Addiction Medicine. Access to Telehealth. 2020. https:// www.asam.org/Quality-Science/covid-19-coronavirus/access-to-telehealth. Accessed 10 Jun 2020

13. Hollander JE, Carr BG. Virtually perfect? Telemedicine for covid-19. N Engl J Med. 2020;382:1679-81. https://doi.org/10.1056/NEJMp2003539.

14. EMCDDA. EMCDDA publishes update on the implications of COVID-19 for people who use drugs and for drug service providers | www.emcdda. europa.eu. http://www.emcdda.europa.eu/news/2020/emcdda-publishesupdate-on-the-implications-of-COVID-19-for-people-who-use-drugs-and-fordrug-service-providers_en. Accessed 4 May 2020.

15. Government of Canada. Exemptions for practitioners and pharmacists prescribing and providing controlled substances, and for patients, during the coronavirus pandemic - Canada.ca. https://www.canada.ca/en/healthcanada/services/health-concerns/controlled-substances-precursor-chemicals/ policy-regulations/policy-documents/section-56-1-class-exemption-patientspharmacists-practitioners-controlled-substances-covid-19-pandemic.html. Accessed 4 May 2020

16. Gupta M, Abdelmaksoud A, Jafferany M, Lotti T, Sadoughifar R, Goldust M. COVID-19 and economy. Dermatol Ther. 2020:e13329. https://doi.org/ 10.1111/dth.13329.

17. de Goeij MCM, Suhrcke M, Toffolutti V, van de Mheen D, Schoenmakers TM, Kunst AE. How economic crises affect alcohol consumption and alcohol-related health problems: a realist systematic review. Soc Sci Med. 2015;131:131-46.

18. Dubanowicz A, Lemmens P. Impact of the economic recession on addiction-prone behaviours; 2015.

19. Rehm J, Kilian C, Ferreira-Borges C, Jernigan D, Monteiro M, Parry CDH, et al. Alcohol use in times of the COVID 19: Implications for monitoring and policy. Drug Alcohol Rev. 2020;:dar.13074. doi:https://doi.org/10.1111/dar.13074.

20. Dom G, Samochowiec J, Evans-Lacko S, Wahlbeck K, Van Hal G, McDaid D. The impact of the 2008 economic crisis on substance use patterns in the countries of the European Union. Int J Environ Res Public Health. 2016;13(1): 122. https://doi.org/10.3390/ijerph13010122.

21. Chou KL, Liang K, Sareen J. The association between social isolation and DSM-IV mood, anxiety, and substance use disorders: wave 2 of the national epidemiologic survey on alcohol and related conditions. J Clin Psychiatry. 2011;72:1468-76.

22. Henkel D. Unemployment and substance use: a review of the literature (1990-2010). Curr Drug Abuse Rev. 2011;4:4-27.

23. Boden JM, Lee JO, Horwood L, Grest CV, McLeod GFH. Modelling possible causality in the associations between unemployment, cannabis use, and alcohol misuse. Soc Sci Med. 2017;175:127-34.

24. European Monitoring Centre for Drugs and Drug Addiction. EU Drug Markets — Impact of COVID-19 | www.emcdda.europa.eu. https://www. emcdda.europa.eu/publications/joint-publications/eu-drug-markets-impactof-covid-19. Accessed 10 Jun 2020.

25. García C. España, único gran país europeo que reabrirá los bares antes que los colegios. Vozpopuli. https://www.vozpopuli.com/espana/Espana-Europa-aperturabares-colegios-desescalada_0_1353165897.html. Accessed 10 Jun 2020.

26. ConFAc. ConFac | Confederación de federaciones de Asociaciones Cannábicas. https://confac.org/. Accessed 10 Jun 2020.

27. IWSR. How the US beverage alcohol industry is responding to the COVID-19 crisis - IWSR. https://www.theiwsr.com/how-the-us-beverage-alcoholindustry-is-responding-to-the-covid-19-crisis/. Accessed 4 May 2020

28. Smith RA, Pancevski B. Happy Hour Gets Earlier in Lockdown - WSJ. Wall Street J. 2020. https://www.wsj.com/articles/happy-hour-comes-nearly-everyday-for-social-drinkers-as-coronavirus-keeps-them-home-11588004362. Accessed 4 May 2020.

29. Martin-Carrasco M, Evans-Lacko S, Dom G, Christodoulou NG, Samochowiec J, González-Fraile E, et al. EPA guidance on mental health and economic crises in Europe. Eur Arch Psychiatry Clin Neurosci. 2016;266:89-124.

30. Volkow ND. Stigma and the toll of addiction. N Engl J Med. 2020;382:128990. https://doi.org/10.1056/NEJMp1917360.

31. Brooks SK, Webster RK, Smith LE, Woodland L, Wessely S, Greenberg N, et al. The psychological impact of quarantine and how to reduce it: rapid review of the evidence. Lancet. 2020;395:912-20.

32. Drummond C. Cuts to addiction services are a false economy. BMJ (Online). 2017;357:j2704. https://doi.org/10.1136/bmj.j2704.

33. Kruse CS, Lee K, Watson JB, Lobo LG, Stoppelmoor AG, Oyibo SE. Measures of effectiveness, efficiency, and quality of telemedicine in the management of alcohol abuse, addiction, and rehabilitation: systematic review. J Med Internet Res. 2020;22:e13252.

34. Hoch E, Preuss UW, Ferri M, Simon R. Digital interventions for problematic cannabis users in non-clinical settings: findings from a systematic review and meta-analysis. Eur Addict Res. 2016;22:233-42. https://doi.org/10.1159/ 000445716.

35. Kaner EF, Beyer FR, Garnett C, Crane D, Brown J, Muirhead C, et al. Personalised digital interventions for reducing hazardous and harmful alcohol consumption in community-dwelling populations. Cochrane Database Syst Rev. 2017;9:CD011479. https://doi.org/10.1002/14651858. CD011479.pub2.

36. Molfenter T, Brown R, O'Neill A, Kopetsky E, Toy A. Use of telemedicine in addiction treatment: current practices and organizational implementation characteristics. Int J Telemed Appl. 2018;2018(Article ID 3932643):7 pages https://doi.org/10.1155/2018/3932643.

37. Barney A, Buckelew S, Mesheriakova V, Raymond-Flesch M. The COVID19 pandemic and rapid implementation of adolescent and young adult telemedicine: challenges and opportunities for innovation. J Adolesc Health. 2020. https://doi.org/10.1016/j.jadohealth.2020.05.006.

38. The COVID-19 APHP Group. Assistance Publique-Hôpitaux de Paris' response to the COVID-19 pandemic. Lancet. 2020;395:1760-1.

39. Ferreri F, Bourla A, Mouchabac S, Karila L e-Addictology: an overview of new technologies for assessing and intervening in addictive behaviors front psychiatry 2018:9:51. doi:https://doi.org/10.3389/fpsyt.2018.00051.

40. Paris M, Silva M, Añez-Nava L, Jaramillo Y, Kiluk BD, Gordon MA, et al. Culturally adapted, web-based cognitive behavioral therapy for Spanishspeaking individuals with substance use disorders: a randomized clinical trial. Am J Public Health. 2018;108:1535-42. https://doi.org/10.2105/AJPH. 2018.304571.

41. Delaigue S, Bonnardot L, Steichen O, Garcia DM, Venugopal R, Saint-Sauveur $J F$, et al. Seven years of telemedicine in Medecins Sans Frontieres demonstrate that offering direct specialist expertise in the frontline brings clinical and educational value. J Glob Health. 2018;8(2):020414. https://doi. org/10.7189/jogh.08.020414.

42. NHS. Crisis resolution and intensive home treatment team (CRHT), urgent care services - Tees Esk and Wear Valleys NHS Foundation Trust. International Labour Office. 2020. https://www.tewv.nhs.uk/services/crisisand-intensive-home-treatment-team/. Accessed 10 Jun 2020.

43. Substance Abuse and Mental Health Services Administration. Chapter 4. Services in Intensive Outpatient Treatment Programs - Substance Abuse: Clinical Issues in Intensive Outpatient Treatment - NCBI Bookshelf. In: Substance Abuse: Clinical Issues in Intensive Outpatient Treatment. 2006. https://www.ncbi.nlm.nih.gov/books/NBK64094/. Accessed 10 Jun 2020.

44. Cornelis J, Barakat A, Dekker J, Schut T, Berk S, Nusselder H, et al. Intensive home treatment for patients in acute psychiatric crisis situations: a multicentre randomized controlled trial. BMC Psychiatry. 2018;18(55). https:// doi.org/10.1186/s12888-018-1632-z.

45. Vieta E, Pérez V, Arango C. Psychiatry in the aftermath of COVID-19. Rev Psiquiatr Salud Ment. 2020. https://doi.org/10.1016/.jpsm.2020.04.004. In press.

46. Gonçalves-Bradley DC, lliffe S, Doll HA, Broad J, Gladman J, Langhorne P, et al. Early discharge hospital at home. Cochrane Database Syst Rev. 2017; 6(6):CD000356. https://doi.org/10.1002/14651858.CD000356.pub4.

47. Alba Palé L, León Caballero J, Córcoles Martínez D, González Fresnedo AM, Bellsolà Gonzalez M, Martín López LM, et al. Psychiatric Home Hospitalization Unit of the Hospital del Mar. A crisis resolution and home treatment team in Barcelona. Rev Psiquiatr Salud Ment. 2019;12:207-12.

48. Boege I, Corpus N, Schepker R, Kilian R, Fegert JM. Cost-effectiveness of intensive home treatment enhanced by inpatient treatment elements in child and adolescent psychiatry in Germany: a randomised trial. Eur Psychiatry. 2015;30:583-9. https://doi.org/10.1016/j.eurpsy.2015.01.009.

49. Bellis MA, Hughes K, Nicholls J, Sheron N, Gilmore I, Jones L. The alcohol harm paradox: using a national survey to explore how alcohol may disproportionately impact health in deprived individuals. BMC Public Health. 2016;16:111. https://doi.org/10.1186/s12889-016-2766-x.

50. Algren MH, Bak CK, Berg-Beckhoff G, Andersen PT. Health-risk behaviour in deprived neighbourhoods compared with non-deprived neighbourhoods: a systematic literature review of quantitative observational studies. PLoS One. 2015;10(10):e0139297. https://doi.org/10.1371/journal.pone.0139297. eCollection 2015.

51. Nordeck CD, Welsh C, Schwartz RP, Mitchell SG, Cohen A, O'Grady KE, et al. Rehospitalization and substance use disorder (SUD) treatment entry among 
patients seen by a hospital SUD consultation-liaison service. Drug Alcohol Depend. 2018;186:23-8. https://doi.org/10.1016/j.drugalcdep.2017.12.043.

52. López-Pelayo H, Miquel L, Altamirano J, Bataller R, Caballeria J, Ortega L, et al. Treatment retention in a specialized alcohol programme after an episode of alcoholic hepatitis: impact on alcohol relapse. J Psychosom Res. 2019;116:75-82. https://doi.org/10.1016/J.JPSYCHORES.2018.11.020.

53. Witkiewitz K, Falk DE, Litten RZ, Hasin DS, Kranzler HR, Mann KF, et al. Maintenance of World Health Organization risk drinking level reductions and posttreatment functioning following a large alcohol use disorder clinical trial. Alcohol Clin Exp Res. 2019;43:979-87. https://doi.org/10.1111/ acer. 14018.

54. Charlet K, Heinz A. Harm reduction-a systematic review on effects of alcohol reduction on physical and mental symptoms. Addict Biol. 2017;22: 1119-59.

55. Baxter AJ, Tweed EJ, Katikireddi SV, Thomson H. Effects of Housing First approaches on health and well-being of adults who are homeless or at risk of homelessness: systematic review and meta-analysis of randomised controlled trials. J Epidemiol Community Health. 2019;73:379-87.

56. DiClemente CC, Corno CM, Graydon MM, Wiprovnick AE, Knoblach DJ. Motivational interviewing, enhancement, and brief interventions over the last decade: a review of reviews of efficacy and effectiveness. Psychol Addict Behav. 2017;31:862-87. https://doi.org/10.1037/adb0000318.

57. Friedrichs A, Spies M, Härter M, Buchholz A. Patient preferences and shared decision making in the treatment of substance use disorders: a systematic review of the literature. PLoS One. 2016;11:e0145817. https://doi.org/10. 1371/journal.pone.0145817.

58. Bush P, Drake R, Xie H, McHugo G, Haslett W. The long-term impact of employment on mental health service use and costs for persons with severe mental illness. Psychiatr Serv. 2009;60(8):1024-31. https://doi.org/10. 1176/ps.2009.60.8.1024

59. Luciano A, Metcalfe JD, Bond GR, Xie H, Miller AL, Riley J, et al. Hospitalization risk before and after employment among adults with schizophrenia, bipolar disorder, or major depression. Psychiatr Serv. 2016;67: 1131-8. https://doi.org/10.1176/appi.ps.201500343.

60. UNSDG. UNSDG | Shared responsibility, global solidarity: Responding to the socio-economic impacts of COVID-19. https://unsdg.un.org/resources/ shared-responsibility-global-solidarity-responding-socio-economic-impactscovid-19. Accessed 4 May 2020.

61. International Labour Office. ILO: COVID-19 causes devastating losses in working hours and employment. 2020. https://www.lo.org/global/aboutthe-ilo/newsroom/news/WCMS_740893/lang\%2D\%2Den/index.htm. Accessed 10 Jun 2020.

62. Chisholm D, Moro D, Bertram M, Pretorius C, Gmel G, Shield K, et al. Are the "best buys" for alcohol control still valid? An update on the comparative cost-effectiveness of alcohol control strategies at the global level. J Stud Alcohol Drugs. 2018;79:514-22.

63. SAMSHA. Coronavirus (COVID-19). 2020. https://www.samhsa.gov/ coronavirus. Accessed 10 Jun 2020.

64. European Monitoring Centre for Drugs and Drug Addiction. EMCDDA update on the implications of COVID-19 for people who use drugs and drug service providers | www.emcdda.europa.eu. 2020. https://www. emcdda.europa.eu/publications/topic-overviews/catalogue/covid-19-andpeople-who-use-drugs_en. Accessed 10 Jun 2020.

65. American Society of Addiction Medicine. COVID-19 Coronavirus. 2020. https://www.asam.org/Quality-Science/covid-19-coronavirus. Accessed 16 Jun 2020.

\section{Publisher's Note}

Springer Nature remains neutral with regard to jurisdictional claims in published maps and institutional affiliations.

Ready to submit your research? Choose BMC and benefit from:

- fast, convenient online submission

- thorough peer review by experienced researchers in your field

- rapid publication on acceptance

- support for research data, including large and complex data types

- gold Open Access which fosters wider collaboration and increased citations

- maximum visibility for your research: over $100 \mathrm{M}$ website views per year

At BMC, research is always in progress.

Learn more biomedcentral.com/submissions 